\title{
10-year outcomes post coronary artery bypass grafting in Asian patients with ischemic cardiomyopathy: a comprehensive analysis of survival and cardiac performance
}

\author{
Simon C. Y. Chow, Randolph H. L. Wong, Peter S. Y. Yu, Jacky Y. K. Ho, Joyce W. Y. Chan, \\ Micky W. T. Kwok, Song Wan, Takuya Fujikawa, Malcolm J. Underwood \\ Division of Cardiothoracic Surgery, Department of Surgery, The Chinese University of Hong Kong, Prince of Wales Hospital, 30-32 Ngan Shing \\ Street, Shatin, New Territories Hong Kong, China \\ Contributions: (I) Conception and design: All authors; (II) Administrative support: RHL Wong, MJ Underwood; (III) Provision of study materials or \\ patients: PSY Yu, RHL Wong, MJ Underwood; (IV) Collection and assembly of data: All authors; (V) Data analysis and interpretation: All authors; (VI) \\ Manuscript writing: All authors; (VII) Final approval of manuscript: All authors. \\ Correspondence to: Simon C. Y. Chow; Malcolm J. Underwood. Division of Cardiothoracic Surgery, Department of Surgery, The Chinese University \\ of Hong Kong, Prince of Wales Hospital, 30-32 Ngan Shing Street, Shatin, New Territories Hong Kong, China. \\ Email: wwjdsimon@gmail.com; mjunderwood@surgery.cuhk.edu.hk.
}

Background: Coronary artery bypass grafting (CABG) is the standard of care for patients with ischemic cardiomyopathy (ICM). Despite recent evidence supporting the role of CABG, long term outcomes for patients with ICM remain poor and 10-year results post CABG in ICM patients are under-reported, especially among Asians. Uncertainty on whether CABG improves cardiac performance and survival in the long term remains. In this study, we aim to analyze 10-year results concerning cardiac performance and survival post CABG in Asian patients with left ventricular ejection fraction (LVEF) $\leq 35 \%$ and predominant heart failure symptoms, and identify perioperative risk factors affecting long term survival and cardiac function.

Methods: Thirty-six patients with LVEF <35\% who had CABG performed between the year 2006-2009 were selected from local hospital records for retrospective analysis. Outcomes of interest included postoperative cardiac symptoms, LVEF \& 10-year all-cause and cardiac-event free survival. Survival analysis was performed using Kaplan Meier analysis, and predictive factors were identified with log- rank test and logistic regression analysis.

Results: The mean age of the cohort was $62.9 \pm 9.9$ years. Operative mortality within 30 days was $5.6 \%$. The 10 -year all-cause mortality rate was $55.6 \%$. The mean duration of survival was $105.9 \pm 8.3$ months. Of the patients who did not survive till 10 years, $65.0 \%$ died of cardiac-related causes, with non-ST elevation myocardial infarction being the commonest cause. CABG improved LVEF $(24.9 \%$ to $32.2 \%$; $\mathrm{P}<0.001)$ and $66.7 \%$ of patients remained with impaired $\mathrm{LVEF} \leq 35 \%$ post CABG. Post op NYHA class $3-4$ symptoms (OR: $6.3 ; \mathrm{P}=0.012)$ was the only predictive factor for 10 year all-cause mortality and post op LVEF improvement $\geq 5 \%$ (OR: 5.8; 95\% CI, 1.1-29.9; $\mathrm{P}=0.036$ ) was associated with improvement in NYHA class. Completeness of revascularization and viability of myocardium were not predictive of survival or changes in LVEF or NYHA class.

Conclusions: The 10-year survival rates of Asian patients with ICM were similarly disappointing as its counterparts in the west. A majority of patients still suffered from cardiac-event related deaths. Post CABG NYHA class was found to be important in determining success and adequacy of treatment in patients with ICM and improvement in LVEF $\geq 5 \%$ was predictive of improvement of symptoms. Neither completeness of revascularization or presence of myocardial viability had any impact on survival in our patient cohort.

Keywords: Oronary artery disease (CAD); coronary artery bypass; cardiomyopathies; myocardial ischemia

Submitted Jul 03, 2019. Accepted for publication Nov 19, 2019.

doi: $10.21037 /$ jtd.2019.12.72

View this article at: http://dx.doi.org/10.21037/jtd.2019.12.72

(C) Journal of Thoracic Disease. All rights reserved. 


\section{Introduction}

Coronary artery disease (CAD) with impaired left ventricular ejection fraction (LVEF) is associated with high risks of mortality and morbidity. Patients are at risk of sudden death, ventricular arrhythmias and debilitating heart failure or anginal symptoms requiring repeated hospital admissions. Not only is this a major burden to healthcare institutions, choosing the appropriate management strategy for these patients is often challenging. CAD is the predominant etiology of left ventricular dysfunction (1), making up $60 \%$ of patients in the Acute Decompensated Heart Failure National Registry (2). Despite its significance, the role of CABG in ischemic cardiomyopathy (ICM) is understudied and guidance on the appropriate treatment for ICM is lacking. Historical studies have either excluded patients with poor LVEF or just included cardiomyopathy as part of subgroup analysis. Additional studies have showed a benefit in CABG in impaired LVEF with anginal symptoms but not so in patients with predominant heart failure symptoms. The STICH trial (3) is the only randomized controlled trial to date that has helped define the place of CABG in ICM, and CABG is now established as the first line therapy for patients with ICM and anatomy suitable for CABG.

However, there is still lingering uncertainties about appropriate patient selection for CABG and doubts exist about the mechanism as to how successful revascularization translates into improved patient outcomes. Apparently, heart failure itself is a complex syndrome, and it is clear that outcomes do not solely hinge on the success of a single treatment modality $(4,5)$. To further one's understanding, one must seek wisdom from past experiences. To our knowledge, reports on 10-year survival of ICM patients post CABG are few, and especially so in the locality of South East Asia. In our analysis we aim to study the long-term survival outcomes of patients with ICM and predominant heart failure symptoms post CABG in a cohort of patients in Hong Kong. Another important objective of this study is to compare the changes in cardiac performance and symptoms before and after CABG in patients with ICM, as well as to analyze association of various perioperative factors with survival and post-operative cardiac symptoms and performance.

\section{Methods}

Between 2006-2009, 36 out of 676 (5\%) patients underwent coronary artery bypass grafting (CABG) for ischemic cardiomyopathy (ICM) at the Prince of Wales Hospital, Hong Kong. These patients were selected from a local cardiac surgery registry and relevant clinical data were retrospectively extracted from electronic patient records for further analysis. Inclusion criteria for analysis included (I) age $\geq 18$; (II) presence of predominant heart failure symptoms despite medical therapy; (III) documented LVEF of $\leq 35 \%$ from echocardiographic study; (IV) coronary artery anatomy suitable for coronary artery bypass grafting. All patient data had been secured and kept confidential.

The primary outcome of interest was 10-year all-cause survival. All 36 patients had data reviewed up to 10 years after CABG. Secondary outcomes were also analyzed and included 10-year cardiac-event related mortality rates, post-operative New York Heart Association (NYHA) classification and post-operative LVEF. Cardiac related mortality was defined as deaths relating to cardiovascular causes including sudden deaths due to ventricular arrhythmias or unknown causes, cardiac pump failure, myocardial infarction (MI), procedural related death and cerebrovascular attacks.

Procedural records were retrospectively analyzed and operative factors were taken into account. Completeness of revascularization was defined as the number of distal anastomosis completed in accordance with the number of diseased coronary vessels with stenosis $\geq 70 \%$ in correspondence to respective coronary territories. Surgeon's appraisal for the quality of coronary vessels was recorded and reviewed. Quality of coronary vessel was classified into 4 groups: (I) good; (II) moderate patchy disease; (III) severe diffused disease; (IV) require endarterectomy. Diameters of distal native vessels $<$ or $\geq 1.5 \mathrm{~mm}$ were also recorded. Guideline directed medical therapy (GDMT) was defined as the use of antiplatelet agents, beta-blocker, angiotensin converting enzyme inhibitor/angiotensin receptor blocker statins and diuretics.

\section{Statistical analysis}

The perioperative 10-year data was analyzed using IBM SPSS statistics ${ }^{\circledR}$ Version 25. Continuous variables are presented as mean \pm standard deviations. Categorical variables are expressed as frequencies and percentages. Kaplan-Meier analysis was performed for survival analysis. Differences between means were calculated with student $t$ test, and differences between frequencies were compared with Chi-square test, with $\mathrm{P}$ values $\leq 0.05$ considered 
Table 1 Baseline characteristics of patients

\begin{tabular}{|c|c|}
\hline Patient baseline characteristics $(n=36)$ & $\begin{array}{l}\text { Mean } \pm \text { SD or } \\
\text { frequencies (\%) }\end{array}$ \\
\hline Mean age (years) & $62.9 \pm 9.9$ \\
\hline Male & $30(83.3)$ \\
\hline Smoking history & $24(66.7)$ \\
\hline Diabetes & $35(97.2)$ \\
\hline Insulin dependent & $3(8.5)$ \\
\hline Hypertension & $35(97.2)$ \\
\hline $\begin{array}{l}\text { Renal disease (impaired creatinine } \\
\text { clearance) }\end{array}$ & $26(72.2)$ \\
\hline Dependent on dialysis & $1(2.8)$ \\
\hline $\begin{array}{l}\text { Pulmonary disease on regular } \\
\text { bronchodilators }\end{array}$ & $1(2.8)$ \\
\hline Neurological disease (prior CVA) & $2(5.6)$ \\
\hline \multicolumn{2}{|l|}{ Cardiac history } \\
\hline \multicolumn{2}{|l|}{ NYHA class } \\
\hline Class I & $7(19.4)$ \\
\hline Class II & $10(27.8)$ \\
\hline Class III & $16(44.4)$ \\
\hline Class IV & $3(8.3)$ \\
\hline Prev. myocardial infarction & $30(83.3)$ \\
\hline$<30$ days & $18(60)$ \\
\hline$>30$ days & $12(40)$ \\
\hline \multicolumn{2}{|l|}{ Nature of operation } \\
\hline Emergency & $4(11.1)$ \\
\hline Surgery within inpatient stay & $4(11.1)$ \\
\hline Elective & $28(77.8)$ \\
\hline Extent of coronary disease & $2.75 \pm 0.5$ \\
\hline Triple vessels disease & $28(77.8)$ \\
\hline Two vessels disease & $7(19.4)$ \\
\hline Single vessel disease & $1(2.8)$ \\
\hline Left main involvement & $14(38.9)$ \\
\hline Pre op LVEF (\%) & $24.9 \pm 5.2$ \\
\hline Logistic Euroscore (mean) & $11.7 \pm 2.7$ \\
\hline Viability study pre-CABG & $21(58.3)$ \\
\hline Nuclear perfusion study & $11(52.4)$ \\
\hline MRI & $7(33.3)$ \\
\hline Stress echocardiography & $3(14.3)$ \\
\hline
\end{tabular}

Table 1 (continued)
Table 1 (continued)

\begin{tabular}{lr}
\hline Patient baseline characteristics $(\mathrm{n}=36)$ & $\begin{array}{r}\text { Mean } \pm \text { SD or } \\
\text { frequencies (\%) }\end{array}$ \\
\hline $\begin{array}{l}\text { Presence of LV segment akinesia on echo } \\
\text { Presence of non-viable segment on } \\
\text { viability study }\end{array}$ & $9 / 21(42.9)$ \\
One vessel territory non-viable & $7(77.8)$ \\
Two vessel territory non-viable & $2(22.2)$ \\
\hline
\end{tabular}

statistically significant.

Univariate analysis of perioperative factors predictive of survival were analyzed with the log-rank test. Significant predictors of mortality had $\mathrm{P}$ values $\leq 0.05$. Analysis of association between categorical or continuous variables and outcomes of interest were performed with binary logistic regression studies. If more than one factor was found to be associated with an outcome, multivariate analysis was performed to adjust for confounders.

\section{Results}

\section{Patient demographics}

Table 1 displays the baseline characteristics of the studied population. The mean age of the cohort was $62.9 \pm 9.9$ years. There was a male predominance in the cohort with $83.3 \%$ male patients. A majority $(97.2 \%)$ of patients had hypertension and diabetes mellitus. The mean logistic Euroscore was $11.7 \pm 2.7$, as a reference, the mean logistic Euroscore for operated patients with preserved LVEF in the same period in our center was 3.1 \pm 1.2 . More than half (52.7\%) of patients were in NYHA class 3-4 symptoms before CABG despite on GDMT. The use of GDMT was $94 \%$. Two thirds $(60 \%)$ of patients had myocardial infarction within 30 days of operation. The mean number of diseased coronary vessels with stenosis $\geq 70 \%$ was $2.75 \pm 0.5$. Most (77.8\%) patients had triple vessels disease and 38.9\% had left main stem disease. The mean pre operation LVEF was $24.9 \% \pm 5.2 \%$ and $61.1 \%$ of patients had akinesia on echocardiogram. More than half $(58.3 \%)$ of patients had viability study performed before CABG, with $52.4 \%$ having had a nuclear perfusion scan and $33.3 \%$ MRI viability test. Less than half $(42.9 \%)$ of the population had presence of non-viable segments, and $22.2 \%$ of these patients had nonviable myocardium across 2 coronary territories. 
Table 2 Procedural details

\begin{tabular}{lc}
\hline Operative details & $\begin{array}{c}\text { Mean } \pm \text { SD or } \\
\text { frequencies }(\%)\end{array}$ \\
\hline Bypass time (min) & $101.8 \pm 35.5$ \\
Ischemic time (min) & $60.4 \pm 33.6$ \\
No. of distal anastomosis & $2.9 \pm 0.8$ \\
1 & $1 / 36(2.8)$ \\
2 & $4 / 36(11.1)$ \\
3 & $25 / 36(69.4)$ \\
4 & $6 / 36(16.7)$ \\
Left internal mammary artery use & $35 / 36(97.2)$ \\
Arterial graft use & $0.9 \pm 0.2$ \\
Vein graft use & $1.9 \pm 0.7$ \\
Complete revascularization & $31 / 36(86.1)$ \\
Post op inotrope usage (any inotrope) & $34 / 36(94.4)$ \\
Low dose (<10 mL/h) & $31 / 34(91.2)$ \\
Moderate to high dose $(>10 \mathrm{~mL} / \mathrm{h})$ & $3 / 34(8.8)$ \\
IABP use (before/after CABG) & $6 / 36(16.7)$ \\
Severe diffused disease $(\mathrm{n}=31)$ & $14 / 31(45.2)$ \\
No. of native target vessels $<1.5 \mathrm{~mm}$ & $49 / 91(53.8)$ \\
\hline
\end{tabular}

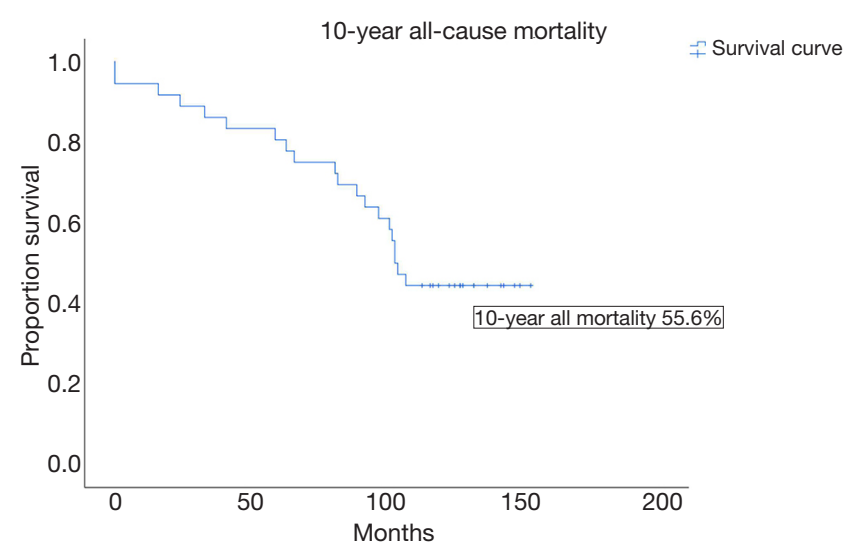

Figure 1 Kaplan-Meier analysis-overall population 10-year allcause mortality.

\section{Procedural details}

Table 2 summarizes the procedural details. $88.9 \%$ of patients had CABG in an elective setting. The mean number of distal anastomosis performed was $2.9 \pm 0.8$. The use of left internal mammary artery (LIMA) was $97.2 \%$, and the mean

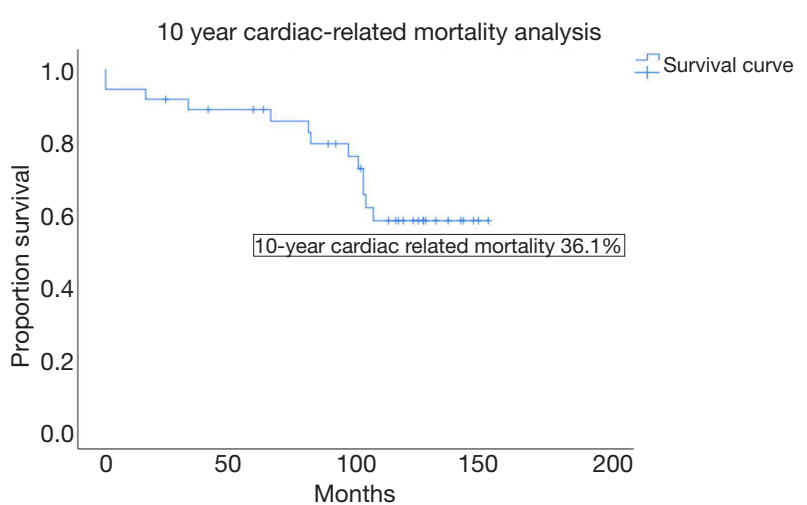

Figure 2 Kaplan-Meier analysis-overall population 10-year cardiac event related mortality.

arterial graft use was $0.9 \pm 0.2$. The average cardiopulmonary bypass time was $101.8 \pm 35.5 \mathrm{~min}$, and ischemic time was $60.4 \pm 33.6 \mathrm{~min}$. The rate of complete revascularization was $86.1 \% .45 .2 \%$ patients were considered to have severe diffusedly diseased coronaries and $53.8 \%$ of the grafted distal target vessels were $<1.5 \mathrm{~mm}$.

\section{Survival}

The 30-day mortality rate was $5.6 \%$ and all deaths were procedural related. As a benchmark, the 30-day mortality rate for patients with preserved LVEF operated during the same period was $0.9 \%$. For our cohort with ICM , the 10 -year all cause mortality rate by the Kaplan Meier analysis was $55.6 \%$, and the mean survival duration was $105.9 \pm 8.3$ months (Figure 1). Actuarial survival by life tables showed a similar survival rate of $44 \%$ at 10 years. $65 \%$ of deaths at 10 years were cardiac-related. The 10 -year cardiac-event free survival was $63.9 \%$ (Figure 2). The commonest cause of cardiac-related death was nonST elevation myocardial infarction (NSTEMI), followed by cardiac pump failure with recurrent and worsening heart failure. For non-cardiac related deaths, the causes of death were evenly distributed amongst gastrointestinal bleeding, malignancy and infection with rates at $28.6 \%$ respectively (Table 3).

\section{Cardiac symptoms and LVEF}

$58.8 \%$ of patients had repeated ( $>1)$ admissions for cardiacrelated events at 10 years. There was a non-significant trend towards improved symptoms post CABG with $32.3 \%$ patients remaining in NYHA class 3-4 symptoms 
Table 3 Results

\begin{tabular}{|c|c|}
\hline Results & $\begin{array}{l}\text { Mean } \pm \text { SD or } \\
\text { frequencies (\%) }\end{array}$ \\
\hline \multicolumn{2}{|l|}{ Survival analysis } \\
\hline Procedural related death within 30 days & $2 / 36(5.6)$ \\
\hline Post op hospital stay (days) & $8.6 \pm 2.1$ \\
\hline 30-day all-cause mortality & 2/36 (5.6) \\
\hline 1-year all-cause mortality & 2/36 (5.6) \\
\hline 5-year all-cause mortality & $7 / 36(19.4)$ \\
\hline 10-year all-cause mortality & 20/36 (55.6) \\
\hline Mean all-cause survival (months) & $105.9 \pm 8.32$ \\
\hline 1-year cardiac event related mortality & $2 / 36(5.6)$ \\
\hline 5-year cardiac event related mortality & $4 / 36(11.1)$ \\
\hline 10-year cardiac event related mortality & 13/36 (36.1) \\
\hline $\begin{array}{l}\% \text { of cardiac death among all-cause } \\
\text { mortality in } 10 \text { years }\end{array}$ & $13 / 20(65.0)$ \\
\hline \multicolumn{2}{|l|}{ Cardiac related deaths } \\
\hline $\begin{array}{l}\text { Repeat congestive heart failure \& } \\
\text { end-stage myocardial failure }\end{array}$ & $4 / 13(30.8)$ \\
\hline NSTEMI & $8 / 13(61.5)$ \\
\hline Procedure related post $\mathrm{CABG}$ & $1 / 13(7.7)$ \\
\hline Non cardiac related & $7 / 20(35.0)$ \\
\hline Gastrointestinal bleeding & $2 / 7(28.6)$ \\
\hline Malignancy & 2/7 (28.6) \\
\hline Infection & $2 / 7(28.6)$ \\
\hline Renal failure & $1 / 7(14.3)$ \\
\hline \multicolumn{2}{|l|}{ Cardiac symptoms and LVEF } \\
\hline \multicolumn{2}{|l|}{ Post op NYHA (n=34) } \\
\hline Class 1 & 11/34 (32.4) \\
\hline Class 2 & 12/34 (35.3) \\
\hline Class 3 & 9/34 (26.5) \\
\hline Class 4 & 2/34 (5.9) \\
\hline Readmission for cardiac events in 10 years & 20/34 (58.8) \\
\hline Post op LVEF (\%) (n=30) & $32.2 \pm 8.9$ \\
\hline LVEF >5\% improvement & $16 / 30(53.3)$ \\
\hline Post op LVEF remained <35\% & $20 / 30(66.7)$ \\
\hline ICD/CRT-D rates & $6 / 36(16.7)$ \\
\hline Guideline directed medical therapy use & 32/34 (94.1) \\
\hline
\end{tabular}

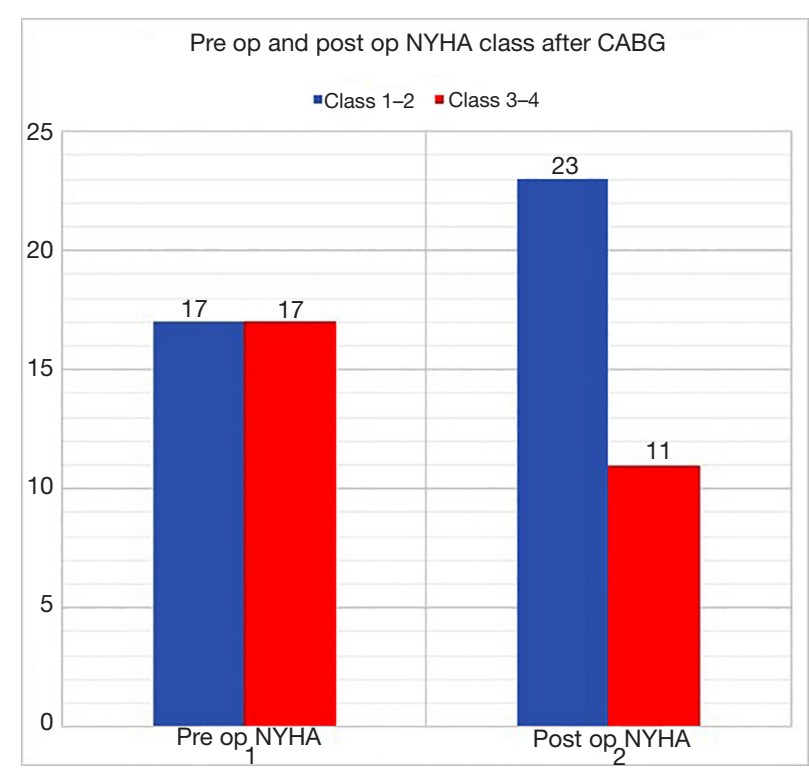

Figure 3 Pre and post CABG NYHA class allocation $(\mathrm{P}=0.14)$.

post $\mathrm{CABG}$ compared to $50 \%$ before $\mathrm{CABG}(\mathrm{P}=0.14)$ (Figure 3). Post CABG mean LVEF improved from $24.9 \%$ to $32.2 \%(\mathrm{P}<0.001)$ (Figure 4). Sixty-six percent of patients post operation remained with LVEF $<35 \%$ and $53.3 \%$ patients had LVEF improvement by $5 \%$ or more. $16.6 \%$ of patients required cardiac resynchronization therapy (CRT) or implantation of implantable cardioverter defibrillator (ICD). The GDMT rate was more than $90 \%$.

\section{Risk factor analysis with survival and changes in cardiac symptoms and LVEF}

Post op NYHA class 3-4 was the only factor associated with 10-year all-cause mortality with OR of 6.3 and $\mathrm{P}$ value $=0.012$. The mean survival of patients in post op NYHA class $3-4$ was $89.7 \pm 11.7$ months $(95 \%$ CI, 66.7-112.7 months), versus $120.3 \pm 8.5$ months (95\% CI, 103.8-136.9 months) in patients with NYHA class $1-2$ symptoms (Figure 5). Improvement in LVEF $\geq 5 \%$ post CABG showed a tendency to improve 10 -year survival, but the effect was not statistically significant $(\mathrm{P}=0.132)$. The presence of diabetes mellitus showed a trend towards worsened 10-year all cause survival (64.3\% vs. $31.8 \%$ 10 -year all cause survival), but the difference was not statistically significant $(\mathrm{P}=0.12)$. All patients with insulin dependent diabetes died at 10 years, but analysis was not 


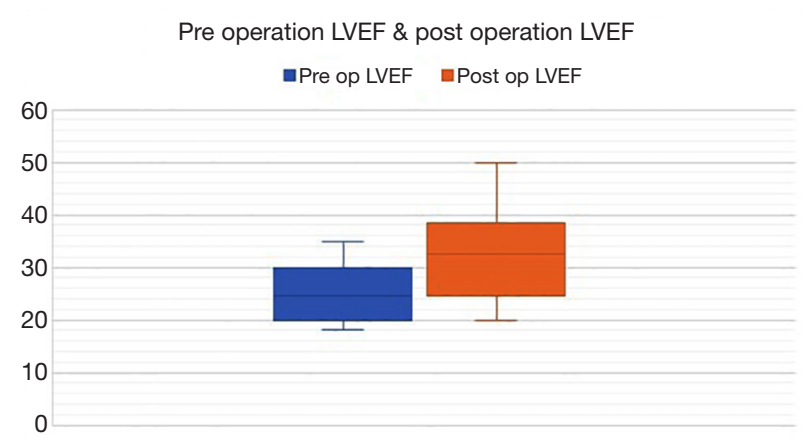

Figure 4 Pre and post CABG LVEF changes $(\mathrm{P}<0.001)$.

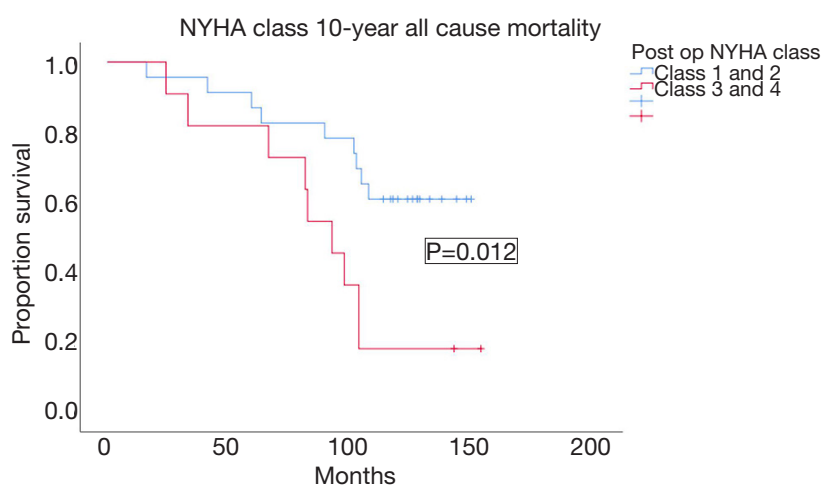

Figure 5 Kaplan-Meier analysis with log-rank test: NYHA class and 10-year all-cause mortality.

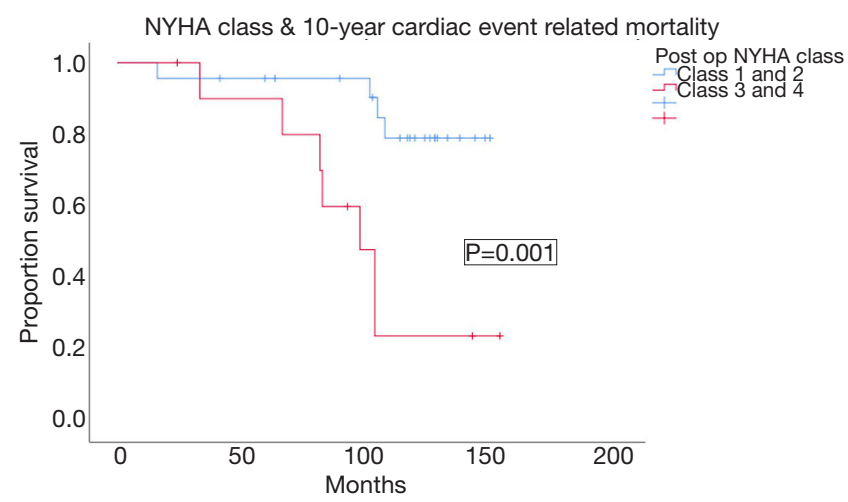

Figure 6 Kaplan-Meier analysis with log-rank test: NYHA class and 10-year cardiac-event related mortality.

possible as the at-risk population was only 4 .

Post op NYHA class 3-4 was also associated with worsened 10 year cardiac-event related mortality, with mean cardiac-related event free survival of $99.3 \pm 11.8$ months in the NYHA class 3-4 group \& $135.7 \pm 6.6$ months in the class $1-2$ group $(\mathrm{P}=0.001)$ (Figure 6).

Complete revascularization and presence of all viable segments was not associated with all cause or cardiac-event related mortality. Neither of the two factors had association with post op LVEF improvement or post op NYHA class.

LVEF improvement by $5 \%$ or more was associated with improvement in NYHA class with OR 5.8 (95\% CI, 1.1-29.9) and $\mathrm{P}=0.036$. In addition, $\mathrm{LVEF}<5 \%$ increase was associated with increased odds of readmission for cardiac events (OR: 6; 95\% CI, 1.0-36.0; P value 0.05). On univariate analysis, absence of diffused coronary disease (OR: 5.5; 95\% CI, 1.0-28.9; $\mathrm{P}=0.04$ ) and presence of graftable targets $\geq 1.5 \mathrm{~mm}$ (OR: 9.6; 95\% CI, 0.98-94.5; $\mathrm{P}=0.05$ ) were associated with LVEF improvement $\geq 5 \%$ post CABG. However neither factors reached a significant correlation with LVEF improvement on multivariate analysis.

\section{Discussion}

Reports of 10 -year survival post CABG in patients with ICM with $\mathrm{LVEF} \leq 35 \%$ are uncommon, especially in Southeast Asia. The Asian population with ischemic heart disease differs from that of the west in that there is a higher incidence of diabetes mellitus among cardiac patients, and generally Asians have smaller body habitus. As a result, coronary targets are often small and the native vessels are commonly heavily diseased in multiple segments with calcified plaques. European guidelines for CABG define appropriate revascularization as grafting of all vessels $1.5 \mathrm{~mm}$ or above with significant stenosis (6), but in our daily practice, $1.5 \mathrm{~mm}$ distal targets are not the norm. In our cohort , $45 \%$ patients had diffusedly diseased coronary disease and $53.8 \%$ had distal grafting sites $<1.5 \mathrm{~mm}$. Hence outcomes from studies from western countries may not be entirely applicable to our patient population. Generally, poor LVEF is associated with higher rates of short term mortality up to 2 years post CABG. In ICM patients, there is a fine balance between survival benefit and operative risk. Subjecting patients to a risky procedure with little chance of improving prognosis and symptoms should best be avoided. Our study offers a comprehensive analysis of 10 -year outcomes of CABG in patients with predominant heart failure symptoms and LVEF $\leq 35 \%$ in an Asian population. The landmark STICH trial remains the only randomized controlled trial on CABG and ICM published to date, and recently the 10-year results were reported in the STICHES trial (7). The 10-year all-cause mortality in 
our cohort is similar to that in the STICHES trial at $45.4 \%$ and $41.4 \%$. The cardiovascular death rate was $40 \%$ in the STICHES trial, while in our population the cardiovascular death rate was $36.3 \%$. It appears that even across different continents, the long-term prognosis of ICM is universally disappointing, and still around $40 \%$ of patients suffered from a cardiovascular death despite revascularization.

The real-life situation of ICM post CABG is sobering, and a reasonable question to ponder is whether $\mathrm{CABG}$ indeed improves cardiac performance and symptoms, and whether survival in patients with ICM is dependent upon improvement in cardiac contractility. In our analysis, we found that CABG improved mean LVEF, but only by a margin of $8 \% .66 \%$ of the patients remained with LVEF $\leq 35 \%$. CABG also improved NYHA symptom class, with more patients moving to NYHA class $1-2$ post operation. Improvements in LVEF by more than $5 \%$ was not associated with improvement in all cause or event free survival, but post operation NYHA class 3-4 symptom was associated with significantly worse prognosis. LVEF improvement $\geq 5 \%$ was positively correlated with improvement in NYHA classification from class 3-4 to class 1-2. Multiple studies demonstrated benefits of CABG in ICM independent of improvement in LVEF $(8,9)$. Samady et al. showed changes in LVEF did not alter outcomes post revascularization (10), while others found improvement in LVEF correlated with improved clinical outcomes $(11,12)$. Clearly, LVEF is not the sole determining factor of survival or symptoms in ICM, and the NYHA classification being a more general clinical appraisal, represents a more holistic assessment of the patient's well-being. Hence it is no surprise that patients in NYHA class 3-4 post revascularization have worse survival. But does improvement in LVEF matter? From the literature worldwide, a few conclusions can be made (13). Firstly, not every patient has improved LVEF post CABG, but if LVEF is improved post CABG, survival is likely better. Secondly, even if there is no improvement in LVEF, revascularization must be conferring benefits other than improvements in contractility that favor survival, such as electrical or rhythm stability or protection against further ischemia. Cardiac remodeling, taking into account heart volumes, is now an important endpoint to determine success or adequacy of treatment in heart failure patients. From the STICH trial, patients with indexed left ventricular end systolic volume $>70 \mathrm{~mL} / \mathrm{m}^{2}$ had worse survival and poorer symptom resolution (14). We did not have these volumes available from the registry records, however it would be interesting to see how many patients achieved remodeling post CABG and how reverse remodeling would impact survival.

To optimize outcomes post CABG, selecting patients that will benefit from revascularization is of great importance. We found that improvement in LVEF $\geq 5 \%$ played a part in improving symptoms, and improvement of heart failure symptoms correlated with better prognosis, but we were not able to identify perioperative factors that would predict LVEF improvement. Univariate analysis showed diffused coronary disease and poor targets had negative effects on LVEF, but the correlation was not significant. The concept of revascularizing hibernating viable myocardium to effect improvement in contractility is of great interest in the management of ICM (15). It seems intuitive that revascularizing viable myocardium should improve cardiac performance, but evidence is inconclusive in this respect. A sub study from the STICH trial did not show any correlation between viability study and survival, and so far no conclusive comparative trials have been able to establish a differentiating role of viability study (16). Allman et al. showed viability testing had a positive impact on prognosis in patients with ICM \& Pagano et al. found that viable myocardium was predictive of symptomatic and functional improvement post CABG $(17,18)$. Di Carli et al. and Pasquet et al. found viable myocardium to be of prognostic value in terms of survival and symptoms improvement $(19,20)$. We were not able to show a positive correlation of improved survival, heart failure symptoms or LVEF with the presence of reversible viable myocardium. This may be explained by the small sample size and heterogeneity in use of different investigations with different accuracies in establishing viability. Around two thirds of our cohort underwent viability study and over $50 \%$ were subjected to nuclear perfusion scans. Cardiac MRI is the current gold standard for assessment of myocardial viability, it allows for revelation of transmurality of infarcts which offers excellent quantification of viability according to late gadolinium enhancement (LGE). Nonetheless, there is no consensus on what extent of non-viability is considered non salvageable by revascularization.

To date, there is no randomized controlled trial comparing percutaneous coronary intervention (PCI) to CABG in ICM. The superiority of CABG in ICM is inferred from large randomized studies on patients with preserved LVEF, and reports in non-randomized trials. In a large registry from New York, propensity matched analysis showed PCI to have lower 30 day stroke risks and comparable survival at 4 years, but with higher rates of revascularization and cardiac events. The main advantages 
of CABG over PCI include complete revascularization, lower rates of repeat revascularization and cardiac events as well as better long term survival (21). These benefits tend to be more pronounced beyond 5 years and the upcoming SYNTAXES trial results show this benefit continues to diverge in favor of CABG at 10 years. It is not unreasonable to assume the benefits of CABG over PCI in patients with ICM , especially the need for repeat revascularization and repeated cardiac events, but it is important to note that patients with ICM are very different from the more commonly encountered population of CAD with preserved LVEF. The pathophysiology behind ICM is more complex and multiple factors decide outcomes. Interestingly, from our data, we could see a disproportionate drop in survival after 5-6 years post CABG. The 5-year all-cause mortality was $19.4 \%$ but rose to $55.6 \%$ at 10 years and the commonest cause of death was cardiac related, with NSTEMI topping the list. In 2006-2009, the transit- time flow meter was not available to document immediate graft flow \& patency, we could not substantiate or review the intraoperative quality of revascularization. While currently in our center all grafts are subject to flow assessment during the operation, it is not a routine practice for us to perform prospective angiograms to evaluate distal quality, hence all distal anastomosis analysis were only performed ad hoc in patients with symptoms or cardiac events. Among the 8 patients with recurrent NSTEMI, only 1 patient had stenotic grafts with percutaneous stenting done to native vessels. This suggests that graft patency may not be the sole cause of NSTEMI. An explanation for the recurrence of cardiac events may be due to the possibility that some of the grafted targets were small with suboptimal runoffs, and that grafting them offered little to no protection from further ischemic events. The 30 -day mortality rate post CABG was $5.6 \%$ in our cohort, which is respectable given the high logistic Euroscore of the group, but this nonetheless serves as a reminder that CABG in ICM patients remains a risky endeavor. This is in stark contrast to the $0.9 \% 30$-day mortality of patients we operated on with preserved LVEF. On the other hand, PCI is a less invasive option with lower risks of short-term stroke risks, shorter length of stay and recovery. The role of PCI cannot be discounted in ICM as the short term risks of PCI is lower than CABG. If long term prognosis for ICM patients remains poor regardless of revascularization by CABG, and uncertainties remain in the success of complete revascularization in the face of poor targets and questionable myocardial viability, more efforts should be devoted to define the role of PCI in ICM (22).
CABG has evolved through the years, and our practice in 2006-2009 was to routinely graft the left internal mammary artery to the left anterior descending artery and saphenous vein grafts to the other coronaries. Off pump CABG is rarely practiced and the use of multiple arterial grafts has not gained traction. Concerns over inotrope induced vasospasm in the post-operative setting and the need to minimize operative and bypass time has limited multiple arterial grafts use in ICM patients. Given the suboptimal patency of saphenous vein grafts, and emerging evidence of improved survival and patency of arterial grafts, it will be interesting to see how total arterial revascularization improves 10-year survival in ICM patients.

This study is small scaled and retrospective in nature, any solid conclusion from this analysis should be conservative. Intrinsic limitations of retrospective analysis include measurement bias, selection bias and lack of control for confounding factors. Association does not imply causation, hence the findings of this study is at best hypothesis generating. In addition there is no comparative group, hence the study is not meant to reach differentiating conclusions among different treatments. It was designed to study outcomes and perform in-depth analysis of patients with ICM who underwent CABG.

As a matter of fact, it must be stressed that uncertainties remain as to how best to achieve improved outcomes in patients with ICM. The emergence of new anti-heart failure medications, antiplatelet agents and catheter-based treatment offers promise in outcome improvement post revascularization. Nonetheless for surgeons, selecting the appropriate patients for CABG remain the most significant part of treatment of ICM. After all, there is more to management of ICM than just a few anastomosis. It goes without saying that patients with ICM should be managed by a multidisciplinary HEART team $(23,24)$.

\section{Conclusions}

Our analysis on a cohort of Asians with ICM and predominant heart failure symptoms has demonstrated similar 10-year survival of ICM post CABG to that of studies from the west. We were able to show that improvement in heart failure symptoms remain the most significant indicator of adequacy of treatment in ICM. Among other factors, improvement in LVEF by $5 \%$ or more predicted symptoms improvement which in turn correlates with 10-year survival. Similar studies on East Asian population are rare, and our study offers insights 
into the ever-expanding field of management of patients with heart failure, especially in Asia where epidemiology differs from the west. We have shown that heart failure is a complex syndrome which requires multi-disciplinary treatment and that revascularization itself may not be adequate to improve survival throughout the years, CABG, PCI and medical therapy have progressed respectively. Past studies were not able to account for this change. More studies are needed to refine revascularization strategies in ICM and more effort should be directed into exploring the role of contemporary PCI and GDMT in ICM. A multidisciplinary approach should be applied in treatment of ICM, and most importantly, appropriate selection of patients should be every surgeon's priority.

\section{Acknowledgments}

Funding: None.

\section{Footnote}

Conflicts of Interest: The authors have no conflicts of interest to declare.

Ethical Statement: The authors are accountable for all aspects of the work in ensuring that questions related to the accuracy or integrity of any part of the work are appropriately investigated and resolved. This cardiac surgical local registry was approved by the Hong Kong Hospital Authority and the Government of Hong Kong SAR to allow collection, analysis, reporting and outcome tracking of patient data since its introduction in 2007.

Open Access Statement: This is an Open Access article distributed in accordance with the Creative Commons Attribution-NonCommercial-NoDerivs 4.0 International License (CC BY-NC-ND 4.0), which permits the noncommercial replication and distribution of the article with the strict proviso that no changes or edits are made and the original work is properly cited (including links to both the formal publication through the relevant DOI and the license). See: https://creativecommons.org/licenses/by-nc-nd/4.0/.

\section{References}

1. Cowie MR, Wood DA, Coats AJ, et al. Incidence and aetiology of heart failure; a population-based study. Eur Heart J 1999;20:421-8.
2. Fonarow GC, Heywood JT, Heidenreich PA, et al. Temporal trends in clinical characteristics, treatments, and outcomes for heart failure hospitalizations, 2002 to 2004: findings from Acute Decompensated Heart Failure National Registry (ADHERE). Am Heart J 2007;153:1021-8.

3. Velazquez EJ, Lee KL, Deja MA, et al. Coronary-artery bypass surgery in patients with left ventricular dysfunction. N Engl J Med 2011;364:1607-16.

4. Yancy CW, Jessup M, Bozkurt B, et al. 2016 ACC/AHA/ HFSA focused update on new pharmacological therapy for heart failure: an update of the 2013 ACCF/AHA Guideline for the Management of Heart Failure: A Report of the American College of Cardiology/American Heart Association Task Force on Clinical Practice Guidelines and the Heart Failure Society of America. J Am Coll Cardiol 2016;68:1476-88.

5. Metra M, Ponikowski P, Dickstein K, et al. Advanced chronic heart failure: a position statement from the Study Group on Advanced Heart Failure of the Heart Failure Association of the European Society of Cardiology. Eur J Heart Fail 2007;9:684-94.

6. Neumann FJ, Sousa-Uva M, Ahlsson A, et al. 2018 ESC/ EACTS Guidelines on myocardial revascularization. The Task Force on myocardial revascularization of the European Society of Cardiology (ESC) and European Association for Cardio-Thoracic Surgery (EACTS). G Ital Cardiol (Rome) 2019;20:1S-61S.

7. Velazquez EJ, Lee KL, Jones RH, et al. Coronary-artery bypass surgery in patients with ischemic cardiomyopathy. N Engl J Med 2016;374:1511-20.

8. Cleland JG, Calvert M, Freemantle N, et al. The Heart Failure Revascularisation Trial (HEART). Eur J Heart Fail 2011;13:227-33.

9. Topkara VK, Cheema FH, Kesavaramanujam S, et al. Coronary artery bypass grafting in patients with low ejection fraction. Circulation 2005;112:I344-50.

10. Samady H, Elefteriades JA, Abbott BG, et al. Failure to improve left ventricular function after coronary revascularization for ischemic cardiomyopathy is not associated with worse outcome. Circulation 1999;100:1298-304.

11. Elefteriades JA, Tolis G Jr, Levi E, et al. Coronary artery bypass grafting in severe left ventricular dysfunction: excellent survival with improved ejection fraction and functional state. J Am Coll Cardiol 1993;22:1411-7.

12. Haxhibeqiri-Karabdic I, Hasanovic A, Kabil E, et al. Improvement of ejection fraction after coronary artery bypass grafting surgery in patients with impaired left 
ventricular function. Med Arch 2014;68:332-4.

13. Tawakol A, Gewirtz H. Does CABG improve LVEF in ischemic cardiomyopathy, and does it matter? J Nucl Med 2001;42:87-90.

14. Jones RH, Velazquez EJ, Michler RE, et al. Coronary bypass surgery with or without surgical ventricular reconstruction. N Engl J Med 2009;360:1705-17.

15. Buckley O, Di Carli M. Imaging of myocardial ischemia and viability: predicting benefit from revascularization in patients with ischemic heart failure. Circulation 2011;123:444-50.

16. Bonow RO, Maurer G, Lee KL, et al. STICH Trial Investigators. Myocardial viability and survival in ischemic left ventricular dysfunction. N Engl J Med 2011;364:1617-25.

17. Allman KC, Shaw LJ, Hachamovitch R, et al. Myocardial viability testing and impact of revascularization on prognosis in patients with coronary artery disease and left ventricular dysfunction: a meta-analysis. J Am Coll Cardiol 2002;39:1151-8.

18. Pagano D, Townend JN, Littler WA, et al. Coronary artery bypass surgery as treatment for ischemic heart failure: the predictive value of viability assessment with quantitative positron emission tomography for symptomatic and functional outcome. J Thorac Cardiovasc Surg 1998;115:791-9.

19. Di Carli MF, Maddahi J, Rokhsar S, et al. Long-term survival of patients with coronary artery disease and

Cite this article as: Chow SCY, Wong RHL, Yu PSY, Ho JYK, Chan JWY, Kwok MWT, Wan S, Fujikawa T, Underwood MJ. 10-year outcomes post coronary artery bypass grafting in Asian patients with ischemic cardiomyopathy: a comprehensive analysis of survival and cardiac performance. $\mathrm{J}$ Thorac Dis 2020;12(3):803-812. doi: 10.21037/jtd.2019.12.72 left ventricular dysfunction: implications for the role of myocardial viability assessment in management decisions. J Thorac Cardiovasc Surg 1998;116:997-1004.

20. Pasquet A, Robert A, D'Hondt AM, et al. Prognostic value of myocardial ischemia and viability in patients with chronic left ventricular ischemic dysfunction Circulation 1999;100:141-8.

21. Bangalore S, Guo Y, Samadashvili Z, et al.

Revascularization in patients with multivessel coronary artery disease and severe left ventricular systolic dysfunction: everolimus-eluting stents versus coronary artery bypass graft surgery. Circulation. 2016;133:2132-40.

22. Perera D, Clayton T, Petrie MC, et al. Percutaneous revascularization for ischemic ventricular dysfunction: rationale and design of the REVIVED-BCIS2 trial: percutaneous coronary intervention for ischemic cardiomyopathy. JACC Heart Fail 2018;6:517-26.

23. Kapur NK, Davila CD, Jumean MF. Integrating interventional cardiology and heart failure management for cardiogenic shock. Interv Cardiol Clin 2017;6:481-5.

24. Ponikowski P, Voors AA, Anker SD, et al. 2016 ESC guidelines for the diagnosis and treatment of acute and chronic heart failure: the Task Force for the diagnosis and treatment of acute and chronic heart failure of the European Society of Cardiology (ESC). Developed with the special contribution of the Heart Failure Association (HFA) of the ESC. Eur J Heart Fail 2016;18:891-975. 